\title{
The Occurrence of Migraine Auras and Possible Triggers
}

\author{
William Burke1,2,3*, John Robinson4 \\ ${ }^{1}$ Brain Research Laboratory, Discipline of Physiology, and Bosch Institute, University of Sydney, Sydney, \\ Australia \\ ${ }^{2}$ Australian Research Council Centre of Excellence in Vision Science, Sydney, Australia \\ ${ }^{3}$ Discipline of Anatomy and Histology, and Bosch Institute, University of Sydney, Sydney, Australia \\ ${ }^{4}$ School of Mathematics and Statistics, University of Sydney, Sydney, Australia \\ Email: william.burke@sydney.edu.au, john.robinson@sydney.edu.au
}

Received 9 September 2014; revised 24 October 2014; accepted 10 November 2014

Copyright @ 2014 by authors and Scientific Research Publishing Inc.

This work is licensed under the Creative Commons Attribution International License (CC BY).

http://creativecommons.org/licenses/by/4.0/

(c) (i) Open Access

\begin{abstract}
Our aim is to determine the cause(s) of migraine auras. Our understanding of how migraines and migraine auras originate is very imperfect. An important observation is that migraines occur more frequently in women at reproductive age than in men at a similar age. This suggests that gonadal hormones may be relevant triggers. The occurrence of classical (typical auras without headache) auras in one author (WB) has been recorded. Every aura in six years (85) has been noted, studied and analysed statistically. The auras occur predominantly in Spring and Autumn, especially in the longer reproductive season of Spring. This association is supported statistically. The results support the idea of gonadal hormones as relevant triggers, the strongest candidate being estrogen. Basic mechanisms underlying the auras are discussed, especially the phenomenon of cortical spreading depression. We also propose that both auras and migraines depend upon previous injury to the head or to the brain, giving rise to a condition of "deafferentation hypersensitivity".
\end{abstract}

\section{Keywords}

Migraine Aura, Equinox, Estrogen, Spring, Autumn, Deafferentation Hypersensitivity

\section{Introduction}

Headaches may be the longest-known medical condition and, among them, migraines may be the best known. In spite of this long history, there is no agreement as to the cause of the migraines. This is probably because migraines are a heterogeneous group. Many are accompanied, usually preceded, by hallucinations mostly either in

${ }^{*}$ Corresponding author. 
the visual or somatosensory modalities. These hallucinations are termed "auras" and can occur in the absence of the headache. Auras are of many different types. Recently [1] it has been reported that in a population of 60 patients experiencing migraines with aura, 65\% of auras are associated with 17 different behaviors or symptoms indicative of brain disorder. This result implies that there is no single cause for an aura. A better chance of reducing the number of possible causes is to concentrate on a single type of aura. We report here the observations of one type of aura in one of us (WB) over a period of six years. This type of aura (HIS 1.2.3.) in this case is "all-or-nothing" and so can safely be termed as a single type of aura. We have therefore studied when these auras occurred in the hope that this might reveal the cause. The frequency of occurrence was measured in relation to the seasons and the ambient temperature. A statistical analysis shows a close relationship between the auras and the seasons adjacent to the solar equinoxes. This implies a gonadal hormonal basis for the auras, and correspondingly for the migraines.

\section{Methods}

WB has been having visual auras without headache for about 13 years. These auras are of the HIS 1.2.3 type (Typical aura without headache), previously known as "classical" or "fortification". These commenced at a time when he experienced a macular hole in his right eye and a macular edema in his left eye. This condition initially led to hallucinations known as the Charles Bonnet Syndrome [2]. Although this syndrome has disappeared, WB still has weak, occasional, geometrical hallucinations in his foveal region. It is assumed that this loss of acuity in central vision was also causative for the auras. There are several good descriptions of these auras [3]-[5]. These auras commence in the point of visual focus, consist of a loop of flickering zig-zag, multi-coloured lines, which enlarges and spreads towards the periphery of vision, taking about 20 minutes to do this, and then disappear. Behind the loop of flickering lights there is a scotomatous area that persists for many minutes. In WB the auras are always unilateral and pain-free. They occur at any time of the day and are not dependent on light. They can occur in sleep; this is known because WB awoke on one occasion when the aura was halfway to the periphery. For the last six years (2008-2013) WB has noted the dates of all his auras. All the auras were experienced in or near Sydney, Australia. In this time WB was abroad for very short periods, at most about one month. He noticed that the auras often occurred near the equinoxes. Because the auras do not occur very often it is convenient to express their occurrence as monthly frequencies.

The dates of the Equinoxes were taken to be 21 March and 23 September. In Australia Spring is defined as 1 September to 30 November and Autumn as 1 March to 31 May. Because of the possibility that the ambient temperature might influence the occurrence of the auras, the daily and average monthly temperatures were obtained from the Australian Bureau of Meteorology (www.bom.gov.au).

Both authors have had full access to all study data.

\section{Statistical Approach}

In order to examine a seasonal effect on aura, we propose to consider a generalised linear model approach. It is assumed that the number of occurrences of auras in a month follows a Poisson distribution with mean an exponential function of a linear regression using the explanatory variables: years, temperature and months (see for example, Chapter 6 of McCullagh and Nelder, 1989) [6]. A means of accounting for seasonal effects is to include a cosine function of months thus making it possible to account for annual and biannual effects (see for example Barnett, Baker and Dobson, 2012) [7]. Annual effects may be expected to be closely related to temperature and biannual effects may be related in time to the equinoxes. We will use the generalised linear model software in R (:A Language and Environment for Statistical Computing, URL: http://www.R-project.org) to fit models and select an appropriate best explanatory model for the data using as a guide the AIC (Akaike Information Criterion, see Akaike, 1974) [8] A detailed description of the analysis is given in an Appendix (Supplementary 1).

\section{Results}

Figure 1 shows the monthly aura frequencies for each of the last six years. There has been a gradual increase in the annual number of auras over these six years: 2008:5; 2009:14; 2010:6; 2011:22; 2012:12; 2013:26. Indeed, the highest monthly frequency (8) occurred in November 2013. It will be noticed that in several years there are 


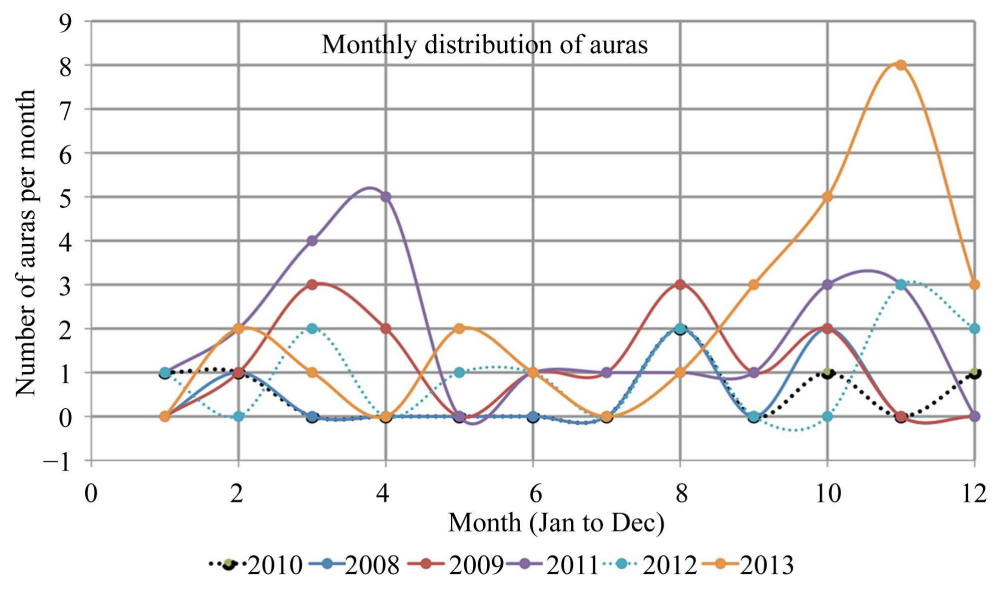

Figure 1. Temporal occurrence of auras. Monthly frequency of auras graphed separately for each of six years. Note the tendency for peaks at month 3 (March), month 8 (August), month 10 (October) and month 11 (November).

peak frequencies at month 3 (March), month 8 (August), month 10 (October) and month 11 (November). These months have an apparent relationship to the climate seasons of Spring and Autumn, especially the equinoxes.

Can the frequency pattern of WB's auras be related to the equinoxes? Figure 2 shows the sum of the yearly graphs depicted in Figure 1. It is clear that the auras fall into two groups centered around the two equinoxes (21 March and 23 September) but the later group is longer, more dispersed and irregular.

Although the equinoxes are strongly associated with reproduction and survival in both animals and plants, these functions are also dependent on several other factors. Therefore, we examined the possibility that the ambient temperature might be a triggering factor. Figure 3 repeats Figure 2 showing the monthly distribution of auras, together with a graph of the mean monthly maximum temperature over the period 2008-2013. There is a similarity between the two distributions, both are roughly U-shaped, but there are also marked differences. This suggests the possibility that temperature is a trigger for the auras, but it is clear that there is no linear relationship and the statistical analysis (below) agrees with that conclusion.

\section{Statistical Analysis}

The best fitting model considered includes as predictor variables the factors Year, Temperature, an effect for comparison of first and second half year, and a seasonal effect modelled by a cosine function with a seasonal cycle corresponding to a biannual or six-monthly effect and a phase parameter determining the start of the cycle. This has the smallest AIC value compared to a series of models obtained by an extensive search and in particular is shown to be preferable to a complete model based on the factors Year and Month ( $P$-value for the test 0.135 and AIC values 211.2 and 209.6). The $P$-values for including the linear effect of Temp, the biannual seasonal effect with phase parameter and half year effect (hY) are $0.1255,0.0404$ and 0.0345 , respectively.

Figure 4(a) shows a plot of the 72 fitted values under this model overlaid with a curve showing the mean of fitted values over years. The line here illustrates both the biannual effects with two maxima near the equinoxes and the effect of the difference between the first and second halves of the year. Figure 4(b) shows the curve from Figure 4(a) together with the curve of mean number of auras per month demonstrating the close relationship of these two curves. Details of the analysis are in the Appendix.

\section{Discussion}

We have described the monthly occurrence of classical auras in one person (WB) over six years and analysed the data statistically.

The conclusion we have reached from our statistical analysis is that the auras have occurred at the times of the year closely associated with the equinoxes, i.e. in the Spring and Autumn seasons. The data in this paper were obtained from a single person, so no general conclusions can be drawn from them. We are not aware of any similar data published anywhere else Nevertheless, there are other different data already available that do sup- 


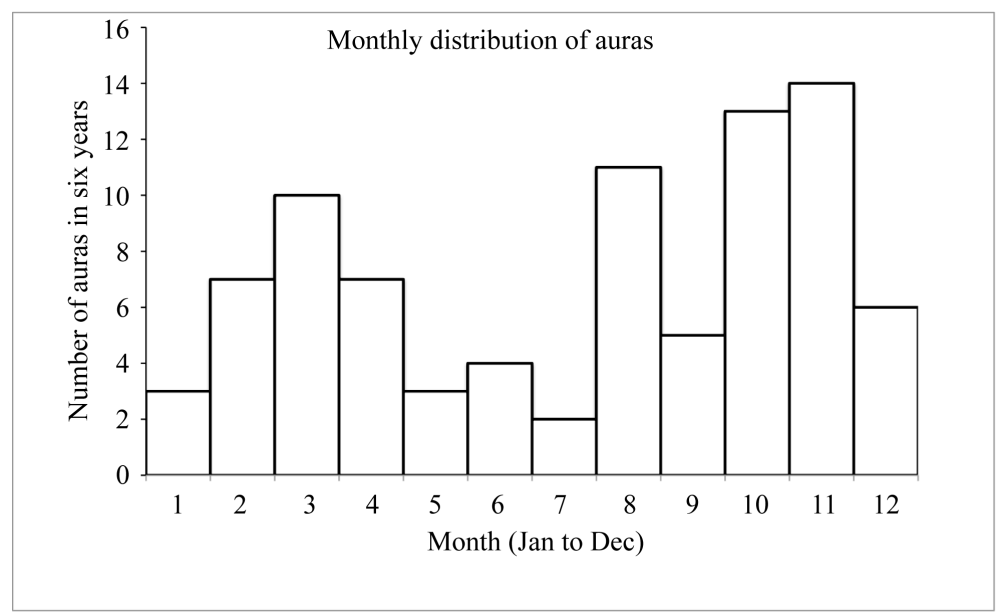

Figure 2. Summary of the aura frequencies over the six years.

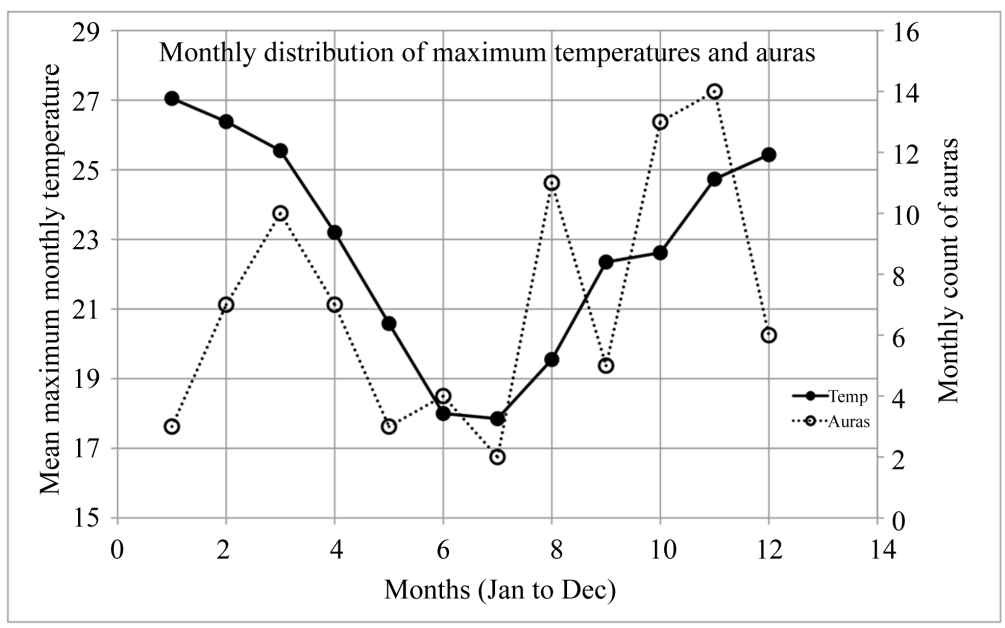

Figure 3. Auras and temperatures. Distribution of all the auras in the six years (open circles and dotted line) and a graph of the mean maximum monthly temperatures (solid circles and solid line) on the same time scale.

port our proposals and will encourage research along similar lines.

\subsection{Equinoxes and Seasons}

The equinoxes occur near the beginnings of the seasons of Spring and Autumn, which are both associated with reproduction. The significant statistical linkage between the auras and the reproductive seasons encourages us to suggest a hormonal trigger for the auras. Although the seasonal dependence of reproduction is strong in most mammals [9], the evidence for humans is contradictory [10] [11]. Nevertheless, especially in the middle to higher latitudes, there is some regulation of reproduction by photoperiodism (influence of day length) [12]. Furthermore, "In the spring a young man's fancy lightly turns to thoughts of love" [13]. As a way of resolving this uncertainty it has been proposed that some humans are seasonally photoresponsive but others are not [11] [14]. Is there a link between reproduction and migraines/auras? One remarkable link concerns the difference between the genders.

\subsection{Gonadal Hormones}

Migraine is three times as common in women of reproductive age as in men of similar age; in women this commonly occurs at menstruation. Attacks of migraine without aura are correlated with "estrogen withdrawal" 

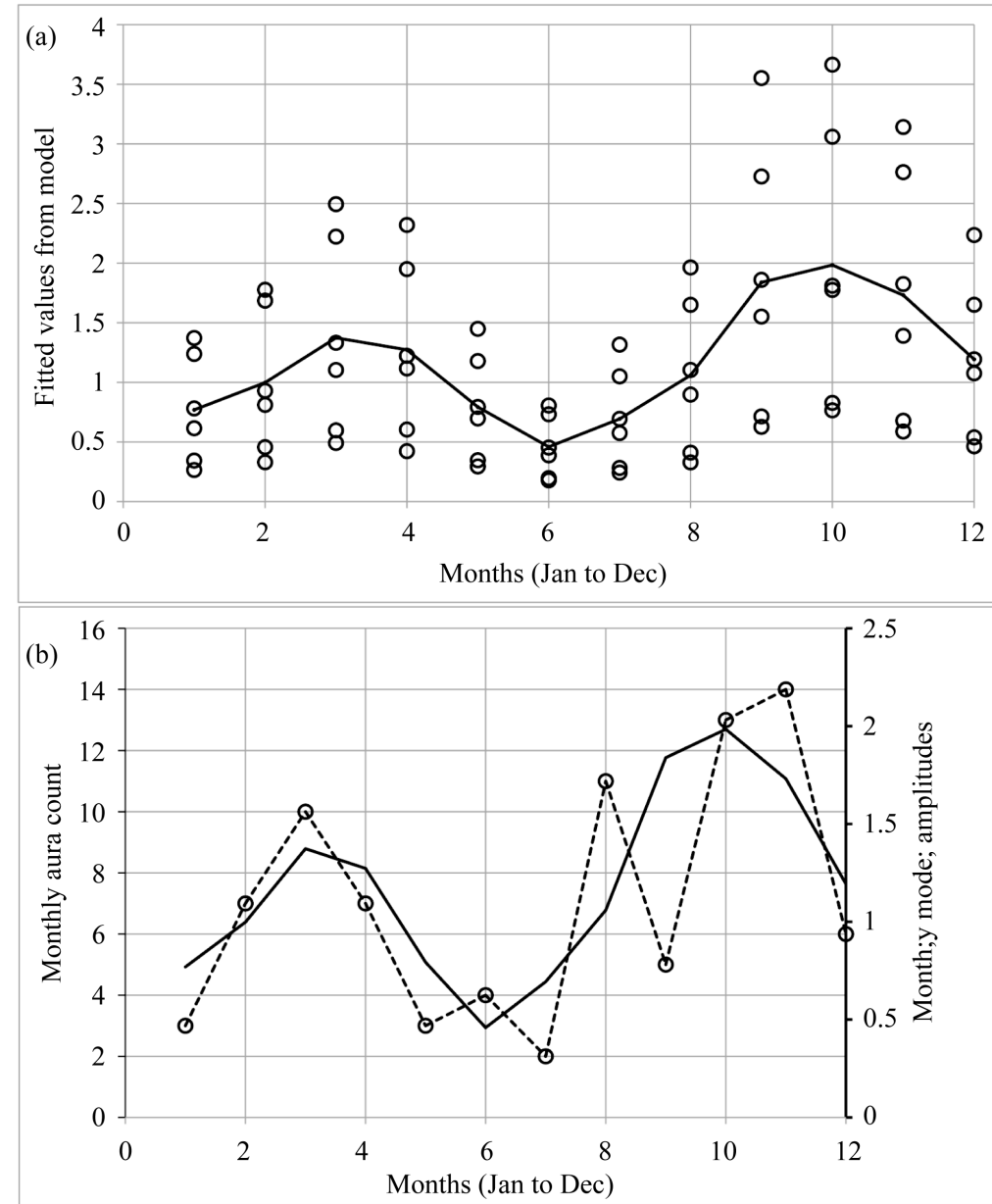

Figure 4. Statistical model. (a) The points are the fitted values obtained from the generalised linear model plotted against months. The line is drawn between average of the fitted points in each month; (b) The solid line from A with the dotted line between average number of auras per month.

[15] [16] whereas migraine with aura is associated with high estrogen levels [17]. The relation between estrogen and attacks of migraine has been well reviewed by MacGregor [18] and more recently the clinical effect of estrogen-modulation to treat migraine has been summarised by Tassorelli and colleagues [19].

\subsection{The Neural Basis of Auras}

There is fairly wide agreement that the underlying basis for the auras is a pathophysiological event called cortical spreading depression (CSD). Although the original account of this phenomenon was due to Leão [20], the interpretation of what occurs during the aura has changed considerably over the years. This is our account of what happens during the aura. We surmise that the aura starts with a large burst of firing in the neurons in the foveal region of the primary visual cortex. A large burst is essential both to create the hallucination and to account for the next step in the process, which is the spreading of the excitation. This is due to local current and the release of potassium from the neurons firing in strong bursts. This depolarises adjacent neurons to threshold and these neurons then fire in bursts and the process continues across the cortex. This is an over-simplification of the process but is a reasonable summary.

It is well established that the cortices of migraineurs are hyperexcitable [21] and so may discharge spontaneously, but a trigger is often needed. In WB's case we believe that there is a deafferentation hypersensitivity due to the loss of input from the foveas of both eyes. Is the hyperexcitability in the cortex of people experiencing auras or migraines due to a marked deafferentation? This needs investigation. 
We suggest also that a feasible trigger for the auras is estrogen. No tests were applied to WB at the time of an aura, simply because it has only recently been realized that a seasonal rhythm existed and that estrogen might be a trigger. We are uncertain how estrogen might act as a trigger to initiate the aura. However, we note that estrogen can elicit seizures when applied to an epileptogenic focus on the cortex [22].

We examined the possibility that temperature might be a trigger for auras but our statistical analysis did not show a significant effect. Nevertheless, with more data and perhaps a different method of analysis the possibility still exists.

In his classical book on Migraine [23] Oliver Sacks raised the question of the possibility of a periodicity of occurrence of migraines, including the difficulty of "demarcating the effects of... undiscovered external cycles.” Indeed, no reliable cycles have been proposed. We hope that a rhythm based on the equinoxes may prove to be an exception.

\section{Conclusion}

Statistically there is a significant correlation between the auras in WB and the seasons of Spring and Autumn. The results support the idea of gonadal hormones as relevant triggers, the strongest candidate being estrogen. The neural mechanism underlying the auras is believed to depend on the phenomenon of cortical spreading depression and in WB's case this is due to deafferentation hypersensitivity. We also propose that both auras and migraines depend upon previous disorder in the head or brain.

\section{Future Research}

1. It is highly desirable that more data be collected on the frequency of occurrence of both auras and migraines. Because this will take up much time it requires many very reliable patients. They should be provided with special diaries and perhaps given some incentives. The easiest task is to collect data on classical (HIS 1.2.3) auras, because these are non-graded, all-or-nothing events. Nevertheless, even an examination of data already collected in clinics might reveal a relationship with Spring and Autumn seasons.

2. The medical history of all migraine patients should be examined to determine what neurological diseases or injuries to the head or brain they have sustained. Is there any evidence of deafferentation hypersensitivity? Attempts should be made t o find correlates between the data and the auras or migraines.

3. Although much research has been done on the role of estrogen in migraine, most of this work has been on women and female animals. The role of gonadal hormones in migraines in men needs extended research, especially the analysis of hormones during auras and migraines.

4. The role of temperature in the occurrence of auras and migraines needs more investigation.

5. An important lesson from the paper of Bronson [14] is that in all studies of photo responsiveness we should pay less attention to population data and concentrate on individual variation. We hope that if attempts are made to seek a correlation between migraines/aura and equinoxes /temperature Bronson’s advice will be heeded.

\section{Conflict of Interest}

Neither author has any conflict of interest.

\section{Financial Support}

We are not in receipt of any research funding. But we are grateful to the University of Sydney for the provision of space and sundry clerical assistance.

\section{Acknowledgements}

We are grateful to Dane King for assistance with the illustrations.

\section{References}

[1] Petrusic, I., Zidverc-Trajkovic, J., Podgorac, A. and Sternic, N. (2013) Underestimated Phenomena: Higher Cortical Dysfunctions during Migraine Aura. Cephalalgia, 33, 861-867. http://dx.doi.org/10.1177/0333102413476373

[2] Burke, W. (2002) The Neural Basis of Charles Bonnet Hallucinations: A Hypothesis. Journal of Neurology, Neuro- 
surgery, 73, 535-541. http://dx.doi.org/10.1136/jnnp.73.5.535

[3] Lashley, K.S. (1941) Patterns of Cerebral Integration Indicated by the Scotomas of Migraine. Archives of Neurology \& Psychiatry, 46, 331-339. http://dx.doi.org/10.1001/archneurpsyc.1941.02280200137007

[4] Richards, W. (1971) The Fortification Illusions of Migraines. Scientific American, 224, 88-96. http://dx.doi.org/10.1038/scientificamerican0571-88

[5] Grüsser, O.-J. (1995) Migraine Phosphenes and the Retino-Cortical Magnification Factor. Vision Research, 35, 11251134. http://dx.doi.org/10.1016/0042-6989(94)00187-Q

[6] McCullagh, P. and Nelder, J.A. (1989) Generalised Linear Models. 2nd Edition, Chapter 6, Chapman and Hall, London. http://dx.doi.org/10.1007/978-1-4899-3242-6

[7] Barnett, A.G., Baker, P. and Dobson, A.J. (2012) Analysing Seasonal Data. The R Journal, 4, 5-10.

[8] Akaike, H. (1974) A New Look at the Statistical Model Identification. IEEE Transactions on Automatic Control, 19, 716-723.

[9] Goldman, B.D. (2001) Mammalian Photoperiodic System: Formal Properties and Neuroendocrine Mechanisms of Photoperiodic Time Measurement. Journal of Biological Rhythms, 16, 283-301. http://dx.doi.org/10.1177/074873001129001980

[10] Bronson, F.H. (1995) Seasonal Variation in Human Reproduction: Environmental Factors. The Quarterly Review of Biology, 70, 141-164. http://dx.doi.org/10.1086/418980

[11] Wehr, T.A. (2001) Photoperiodism in Humans and Other Primates: Evidence and Implications. Journal of Biological Rhythms, 16, 348-364. http://dx.doi.org/10.1177/074873001129002060

[12] De Almeida Ferreira Braga, D.P., Setti, A., de Cássia Sávio Figueira, R., et al. (2012) Seasonal Variability in the Fertilization Rate of Women Undergoing Assisted Reproduction Treatments. Gynecological Endocrinology, 28, 549-552. http://dx.doi.org/10.3109/09513590.2011.649812

[13] Tennyson, A. (1842) Locksley Hall. Macmillan, London. Reprinted in The Poems of Alfred Tennyson. Longman, Harlow, 1969.

[14] Bronson, F.H. (2004) Are Humans Seasonally Photoperiodic? Journal of Biological Rhythms, 19, 180-192. http://dx.doi.org/10.1177/0748730404264658

[15] Sonerville, B.W. (1975) Estrogen-Withdrawal Migraine I. Duration of Exposure Required and Attempted Prophylaxis by Premenstrual Estrogen Administration. Neurology, 25, 239-244. http://dx.doi.org/10.1212/WNL.25.3.239

[16] Somerville, B.W. (1975) Estrogen-Withdrawal Migraine II. Attempted Prophylaxis by Continuous Estradiol Administration. Neurology, 25, 245-250. http://dx.doi.org/10.1212/WNL.25.3.245

[17] Nagel-Leiby, S., Welch, K.M.A., Grunfeld, S. and D’Andrea, G. (1990) Ovarian Steroid Levels in Migraine with and without Aura. Cephalalgia, 10, 147-152. http://dx.doi.org/10.1046/j.1468-2982.1990.1003147.x

[18] MacGregor, E.A. (2004) Oestrogen and Attacks of Migraine with and without Aura. The Lancet, 3, 354-361. http://dx.doi.org/10.1016/S1474-4422(04)00768-9

[19] Tassorelli, C., Greco, R., Allena, M., et al. (2012) Transdermal Hormonal Therapy in Perimenstrual Migraine: Why, When and How? Current Pain and Headache Reports, 16, 467-473. http://dx.doi.org/10.1007/s11916-012-0293-8

[20] Leão, A.A.P. (1944) Spreading Depression of Activity in the Cerebral Cortex. Journal of Neurophysiology, 7, 359-390.

[21] Mulleners, W.M., Chronicle, E.P., Palmer, J.E., et al. (2001) Visual Cortex Excitability in Migraine with and without Aura. Headache, 41, 565-572. http://dx.doi.org/10.1046/j.1526-4610.2001.041006565.x

[22] Marcus, E.M., Watson, C.W. and Goldman, P.L. (1966) Effects of Steroids on Cerebral Electrical Activity. Archives of Neurology, 15, 521-532. http://dx.doi.org/10.1001/archneur.1966.00470170075008

[23] Sacks, O.W. (1970) Migraine. Revised Edition, 1992. Faber and Faber, London. 


\section{Appendix (Supplementary 1)}

\section{Details of the Statistical Approach}

The data are number of aura per month collected over a 6 year period, together with year, month and maximum monthly temperature. A plot of Aura against Month in Figure 1, suggests a possible biannual effect with different maxima in autumn and spring. It is proposed to fit a generalised linear model to take account of these features.

The number of aura per month might be expected to be from a Poisson distribution with mean depending on the variables: year, average maximum temperature of month (Temp), and effects related to seasons. The data are set out as vectors Aura, Year, Temp and Month, each of length 72. So the logarithm of the mean of the Poisson is taken as a linear form:

$$
\mathrm{b} 0+\mathrm{b} 1 * \text { Year2 }+\cdots+\mathrm{b} 5 * \text { Year6 }+\mathrm{b} 6 * \mathrm{Temp}+\mathrm{b} 7 * \mathrm{hY}+\mathrm{b} 8 * \cos (2 * \mathrm{pi} *(\text { Month }-\mathrm{a}) / 6),
$$

where hY takes values 0 for Months 1 to 6 and 1 for months 7 to 12 and the final term represents a biannual effect with starting point a months before mid-January. We note that a seasonal effect $\cos \left(2 * \mathrm{pi}^{*} \mathrm{Month} / 12\right)$ is highly correlated $(r=0.81)$ with Temp and so is excluded. We fitted the parameters b0, ..., b8 using the glm package in the $\mathrm{R}$ language, then maximised the likelihood over the phase parameter a. Many sub-models were fitted to check that we had this best model. The effect of Temp could be removed from the model as this provides effectively the same AIC and a test for the additional effect of fitting Temp is not significant.

A check on the fit can be made visually as in Supplementary Figure 1 which gives the standardised residuals (difference of number of auras per month and their fitted values divided by estimated standard deviation given by the square root of the fitted values). This shows no pattern indicating that the fit may be taken to be adequate. The interpretation of these results is best seen in Figure 4.

The analysis was performed as shown in the following output from R. Note that the estimate of a as 0.7 was made separately by minimising the deviance for different values of a. So, the AIC for the model should be 209.6.

Call:

$\operatorname{glm}($ formula $=$ Aura $\sim$ as.factor $($ Year $)+$ Temp $+\mathrm{hY}+\cos (2 *$ pi $*($ Month -0.7$) / 6)$, family $=$ poisson $)$

Deviance Residuals:

\begin{tabular}{ccccc}
\hline Min & 1Q & Median & 3Q & Max \\
\hline-2.1541 & -1.0948 & -0.2613 & 0.6475 & 2.2887 \\
\hline
\end{tabular}

Coefficients:

Estimate Std. Error z value $\operatorname{Pr}(>|z|)$

\begin{tabular}{ccccc}
\hline (Intercept) & -2.63080 & 1.09124 & -2.411 & $0.01592^{*}$ \\
\hline as.factor(Year)2 & 0.97731 & 0.52200 & 1.872 & 0.06118. \\
as.factor(Year)3 & 0.15639 & 0.60577 & 0.258 & 0.79627 \\
as.factor(Year)4 & 1.45041 & 0.49584 & 2.925 & $0.00344 * *$ \\
as.factor(Year)5 & 0.83494 & 0.53278 & 1.567 & 0.11708 \\
as.factor(Year)6 & 1.54003 & 0.49312 & 3.123 & $0.00179 * *$ \\
Temp & 0.06472 & 0.04225 & 1.532 & 0.12554 \\
hY & 0.48293 & 0.22842 & 2.114 & $0.03450 *$ \\
cos(2 * pi * (Month-0.7)/6) & -0.39862 & 0.15990 & -2.493 & $0.01267 *$ \\
Signif. codes: & & & & 0.05 ë.í \\
\hline
\end{tabular}

(Dispersion parameter for poisson family taken to be 1). 


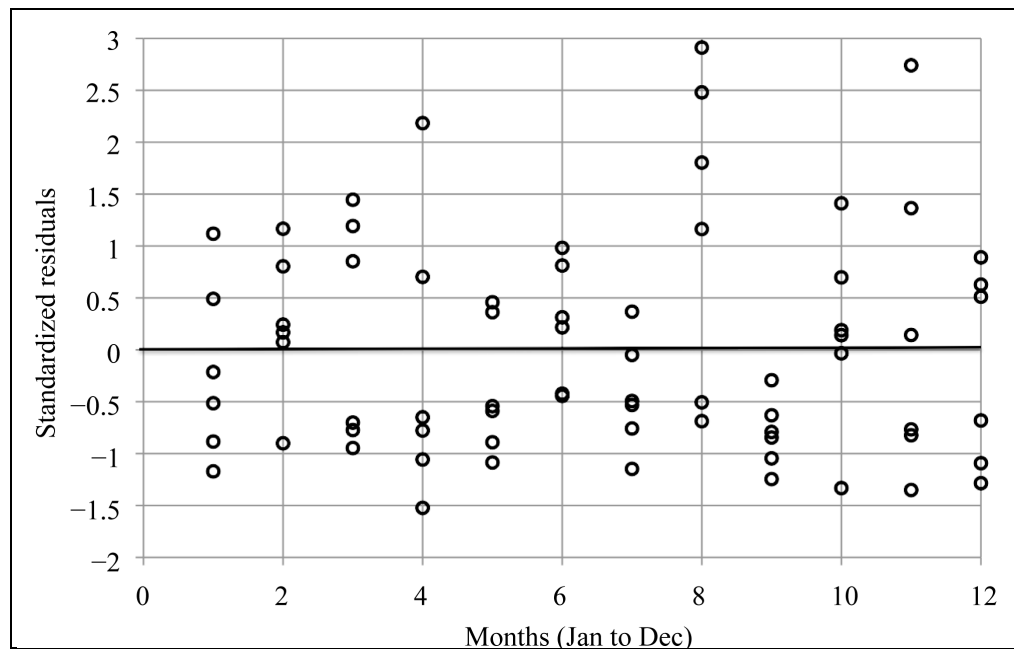

Supplementary Figure 1. Standardised difference of numbers of auras per month and their fitted values plotted against Months. No pattern is evident in these residuals.

Null deviance: 124.973 on 71 degrees of freedom

Residual deviance: 85.736 on 63 degrees of freedom

AIC: 207.6

plot(Month,(Aura-BFMod\$fit)/sqrt(BFMod\$fit),ylab="Standardised Residuals",main="Figure6") abline $(\mathrm{c}(0,0))$ 
Scientific Research Publishing (SCIRP) is one of the largest Open Access journal publishers. It is currently publishing more than 200 open access, online, peer-reviewed journals covering a wide range of academic disciplines. SCIRP serves the worldwide academic communities and contributes to the progress and application of science with its publication.

Other selected journals from SCIRP are listed as below. Submit your manuscript to us via either submit@scirp.org or Online Submission Portal.
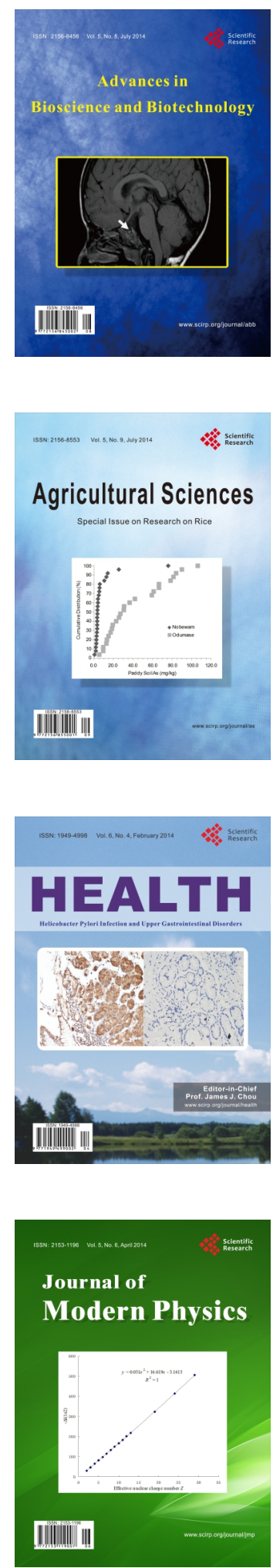
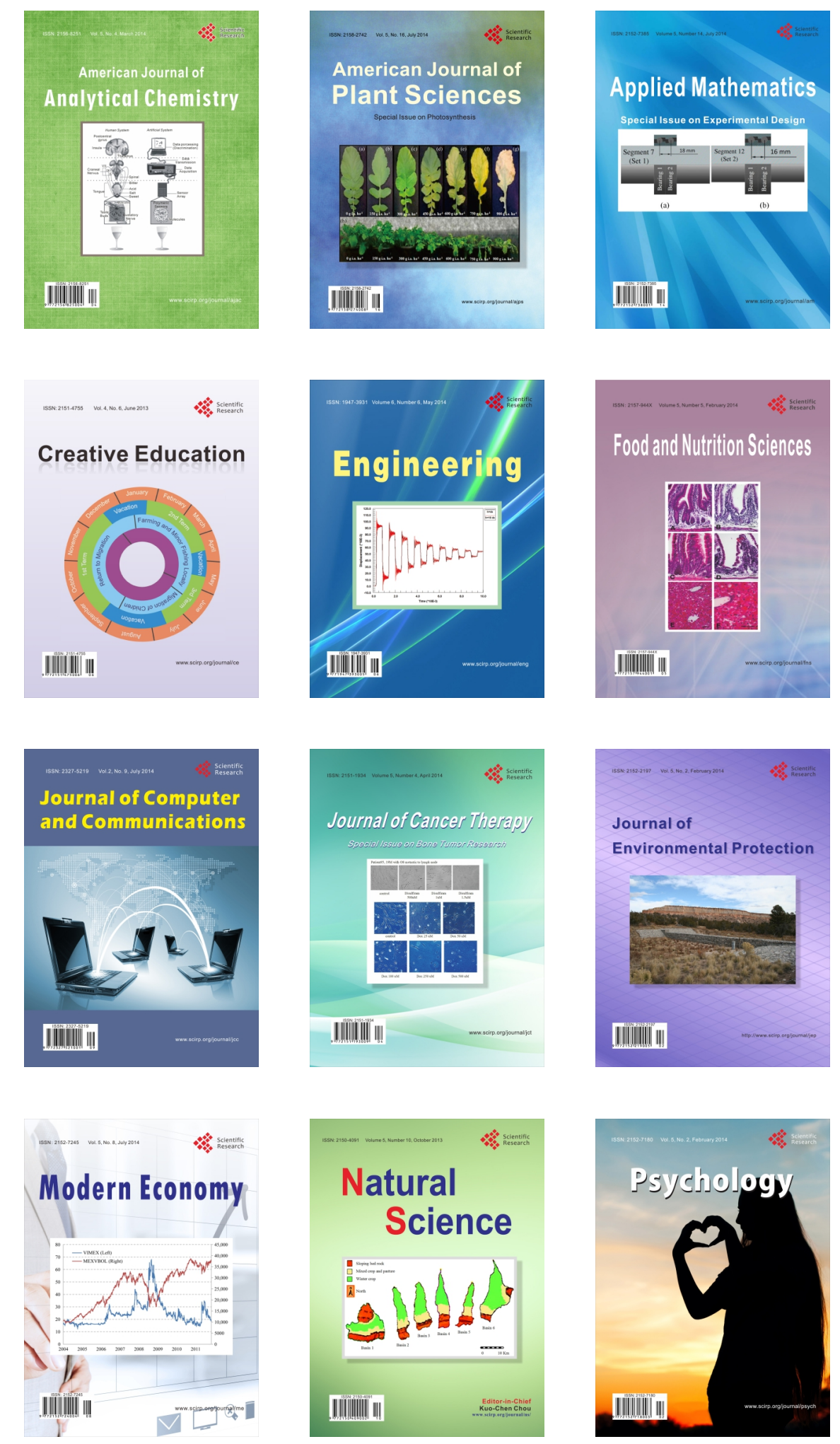